\title{
DIAGNÓSTICO POR IMAgEM DA CAVIDADE ORAL*
}

\author{
Ricardo Pires de Souza ${ }^{1}$, Silvia Regina Pagotto², Ademar José de Oliveira Paes Junior ${ }^{3}$, \\ Aldemir Humberto Soares ${ }^{4}$, Abrão Rapoport ${ }^{5}$
}

\begin{abstract}
Resumo A ressonância magnética e a tomografia computadorizada são importantes métodos de exames complementares para o diagnóstico das doenças da cavidade oral. Aspectos técnicos de cada método são discutidos, assim como suas vantagens e limitações. A anatomia da cavidade oral é revista, assim como alguns aspectos do carcinoma de células escamosas, que é a neoplasia maligna mais freqüente dessa região. Unitermos: Cavidade oral; Tomografia computadorizada; Ressonância magnética.
\end{abstract}

Abstract Imaging diagnosis of the oral cavity.

Magnetic resonance imaging and computed tomography are important additional methods for the diagnosis of oral cavity diseases. The technical aspects of both methods are discussed including their advantages and limitations. The anatomy of the oral cavity is reviewed as well as some characteristics of squamous cell carcinoma, which is the most frequent neoplasia in this region.

Key words: Oral cavity; Computed tomography; Magnetic resonance imaging.

\section{INTRODUÇÃO}

O estudo por imagem da cavidade oral pode servir como guia no diagnóstico e tratamento de doenças bucais, principalmente quando exames clínico, endoscópico e laboratoriais são insuficientes ${ }^{(\mathbf{1})}$. Cerca de $7 \%$ das doenças da cavidade oral são malignas, das quais $90 \%$ têm origem em células escamosas ${ }^{(\mathbf{1})}$. Freqüentemente sua causa principal é o uso abusivo de álcool e de tabaco ${ }^{(1-3)}$. Juntamente com o exame clínico e laboratorial, a tomografia computadorizada (TC) e a ressonância magnética (RM) auxiliam no estadiamento dessa doença, utilizando-se a classificação TNM da União Internacional Contra o Câncer (UICC) ${ }^{(4-6)}$.

Para uma boa avaliação é necessário o conhecimento das estruturas anatômicas e das técnicas possíveis de reprodução das imagens.

* Trabalho realizado no Complexo Hospitalar Heliópolis, São Paulo, SP.

1. Diretor do Serviço de Diagnóstico por Imagem do Complexo Hospitalar Heliópolis.

2. Aluna do Curso de Pós-Graduação em Cirurgia de Cabeça e Pescoço do Complexo Hospitalar Heliópolis.

3. Médico Residente do Serviço de Diagnóstico por Imagem do Complexo Hospitalar Heliópolis.

4. Diretor do Serviço de Diagnóstico por Imagem do Hospital do Servidor Público Estadual de São Paulo.

5. Coordenador do Curso de Pós-Graduação em Cirurgia de Cabeça e Pescoço do Complexo Hospitalar Heliópolis.

Endereço para correspondência: Dr. Ricardo Pires de Souza. Complexo Hospitalar Heliópolis. Rua Cônego Xavier, 276, 10 andar. São Paulo, SP, 04231-030. E-mail: ricapires@ig.com.b

Recebido para publicação em 27/9/2002. Aceito, após revisão, em $7 / 10 / 2002$
Ambos os exames, TC e RM, permitem bons resultados, podendo-se determinar a profundidade e a extensão do tumor com maior precisão ${ }^{(\mathbf{4 - 6})}$.

\section{ASPECTOS TÉCNICOS}

\section{Tomografia computadorizada}

A maior vantagem da TC, em comparação com a RM, é a sua mais rápida aquisição da imagem, a maior disponibilidade de equipamentos e seu menor custo.

Segundo Becker ${ }^{(7)}$, a TC possui exatidão no estadiamento entre $81 \%$ e $94 \%$ em tumores da cavidade oral.

Lenz et al. ${ }^{(4)}$ avaliam que o grande valor da TC é sua capacidade de determinar o real tamanho e infiltração do tumor nas regiões adjacentes.

Ao avaliarmos cada uma das técnicas, observamos vantagens e desvantagens entre elas. A TC permite melhor avaliação óssea da mandíbula e da base do crânio, está menos sujeita a artefatos de movimento e pode-se avaliar a vascularização normal e das lesões mediante injeção endovenosa de meio de contraste iodado ${ }^{(\mathbf{8 , 9})}$. Por outro lado, materiais dentários metálicos interferem no estudo da região oral por causarem grandes artefatos, assim como a densidade óssea e dos dentes. Para amenizar este artefato o paciente deve ficar com a boca entreaberta, com a ajuda de um espaçador.

Um tumor primário com sutil erosão óssea cortical ou alveolar é mais bem ob- servado na TC com cortes coronais. Na TC, os músculos são difíceis de serem diferenciados de tecidos neoplásicos, por apresentarem densidades similares.

\section{Ressonância magnética}

Entre as vantagens sobre a TC, a RM demonstrou um notável contraste entre tecidos moles na avaliação das estruturas da cavidade oral, além da sua capacidade multiplanar de obter imagens coronais, sagitais e axiais, facilitando o planejamento cirúrgico e a identificação da extensão intracraniana dos tumores, especialmente nos forames oval e lácero ${ }^{(\mathbf{1 0 , 1 1 )}}$.

O maior tempo de exame, maior custo e contra-indicação de pacientes com claustrofobia, dispnéia intensa e portadores de implantes podem ser considerados como desvantagens perante a TC.

Na ponderação de imagens em T1, há melhor diferenciação da interface tumorgordura e, por sua vez, em T2 ocorre o mesmo na interface tumor-músculo, sendo mais sensível à presença de doenças do que a TC. Os artefatos causados por materiais metálicos ou pela densidade óssea são pouco significantes. Há boa diferenciação entre lesões císticas ou sólidas. Lesões hipo ou hipervasculares, em função da ausência de sinal ("flow-void"), devido ao fluxo vascular, permite determinar vasos sanguíneos, diferenciação com linfonodos, com eficiência, sem a utilização de material de contraste endovenoso. 
No entanto, imagens pesadas em T2 podem superestimar dimensões tumorais. Ao utilizar o meio de contraste paramagnético (gadolínio endovenoso), reduz-se o tempo de relaxação longitudinal (T1), aumentando a intensidade de sinal da área impregnada, melhorando a delineação dos tumores vascularizados e reduzindo o sobreestadiamento provocado, por exemplo, por edema perilesional $^{(\mathbf{1 2})}$. Em muitos casos a diferenciação entre lesões inflamatórias reacionais e neoplasias é inespecífica. Nota-se claramente a necessidade de conhecimentos técnico e anatômico para a obtenção de melhores imagens de RM.

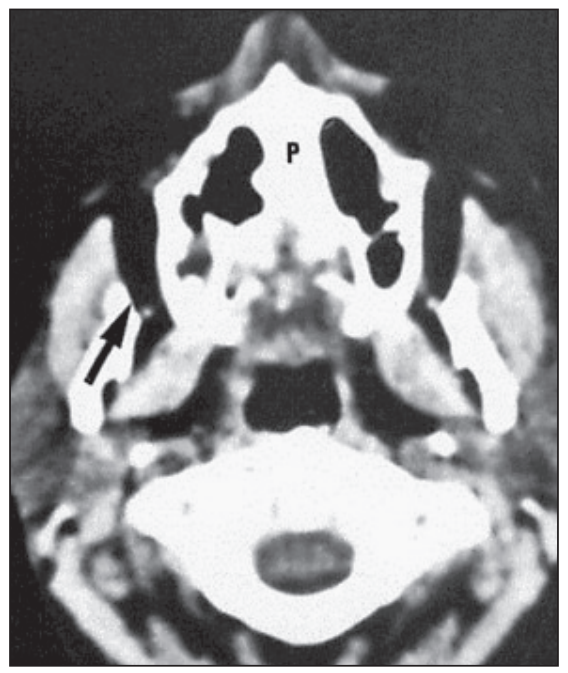

Figura 1. Palato duro normal. Corte axial de tomografia computadorizada, janela de partes moles. Notar estrutura óssea do palato duro (P). Observar, ainda, a região do trígono retromolar, em frente à margem anterior do ramo da mandíbila (seta).
Pequenos tumores são mais homogêneos, porém mais pobremente definidos, e grandes tumores podem apresentar-se heterogêneos, com necrose central, com intensidade de sinal alta, como tumores sólidos. A RM é superior à TC quanto à detecção de pequenos tumores.

\section{ANATOMIA E AVALIAÇÃO DOS TUMORES}

A cavidade oral inclui lábios, palato duro, processos alveolares superiores e inferiores, dois terços anteriores da língua, mucosa bucal, região do trígono retromolar e soalho da boca, incluindo o vestíbulo (espaço entre os lábios externamente e os dentes e gengivas internamente).

A cavidade oral, em toda a sua extensão, é revestida por epitélio escamoso.

Os anexos principais da cavidade oral incluem glândulas salivares submandibulares e sublinguais e estruturas ósseas de suporte, como a mandíbula e a maxila. A cavidade oral possui dois tipos principais de tecidos moles: músculos e gordura.

\section{Lábios}

O carcinoma de células escamosas (CEC) de lábio é a mais comum neoplasia da cavidade oral. Tanto na TC como na $\mathrm{RM}$ o tumor primário pode aparecer como uma massa com ou sem área de ulceração.

Inicia-se no vermelhão labial, invadindo o músculo orbicularis orbis e pele adjacente. Os mais avançados podem envolver mucosa bucal, mandíbula e, eventual- mente, o nervo mentoniano. Pode seguir uma rota para dentro da cavidade medular da mandíbula e seguir ao longo da terceira divisão do nervo trigêmeo.

\section{Palato duro}

Área semilunar, que se estende desde a superfície interna da borda alveolar superior até a margem posterior do osso palatino.

Os CEC de palato duro freqüentemente estão confinados nos seus sítios de origem até o diagnóstico.

Tumores avançados podem invadir a maxila, cavidade nasal, mucosa bucal, língua, ou a região do trígono retromolar. Portanto, cortes coronais são extremamente necessários para avaliar esses tumores.

\section{Processo alveolar superior}

Margem constituída pelo processo alveolar da maxila e seu revestimento mucoso. Estende-se desde a fixação da mucosa na goteira gengivobucal superior até a transição com o palato duro. Seu limite posterior é a extremidade superior do arco pterigopalatino.

A TC é usualmente utilizada para detectar tumores nesta região.

\section{Processo alveolar inferior}

Composto pelo processo alveolar da mandíbula e que, posteriormente, segue pelo ramo ascendente desta.

O CEC com invasão óssea é manifestação tardia dificilmente diagnosticada clinicamente. Conforme o envolvimento ósseo

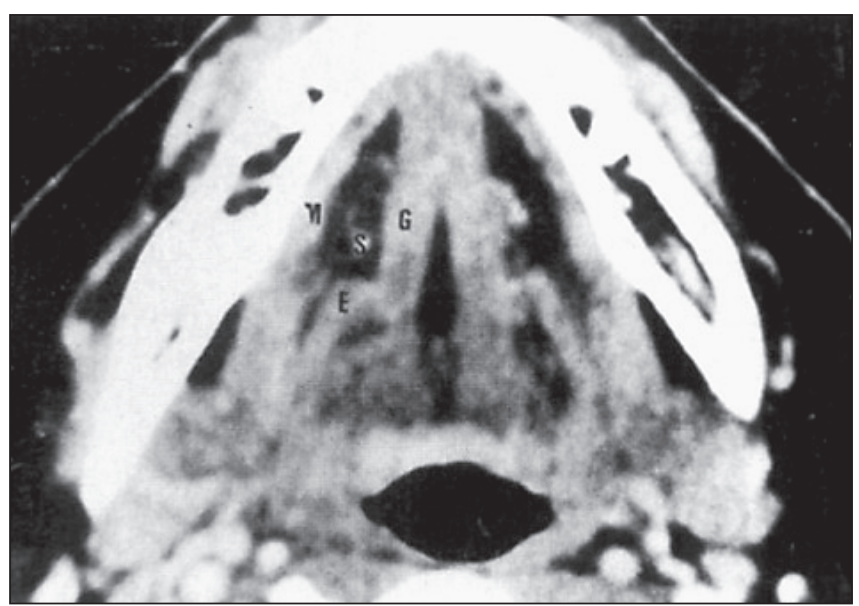

Figura 2. Soalho da boca normal. Corte axial de tomografia computadorizada, janela de partes moles. Complexo hioglosso-estilo-hioglosso (E), músculo genio-hioglosso (G), espaço sublingual (S) e músculo milo-hióideo (M).

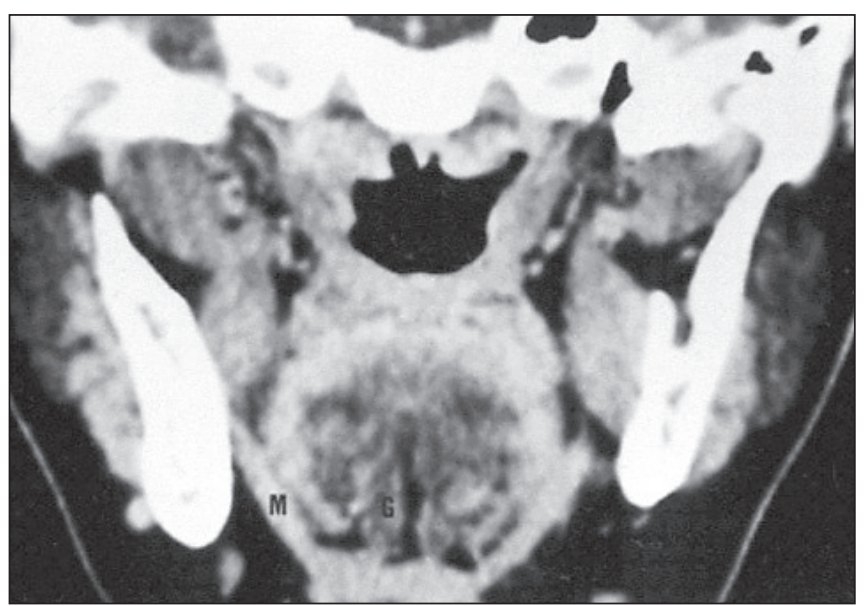

Figura 3. Soalho da boca normal. Corte coronal de tomografia computadorizada, janela de partes moles. Observar a imagem do músculo genioglosso e diafragma do soalho da boca (formado pelo músculo milo-hióideo). 


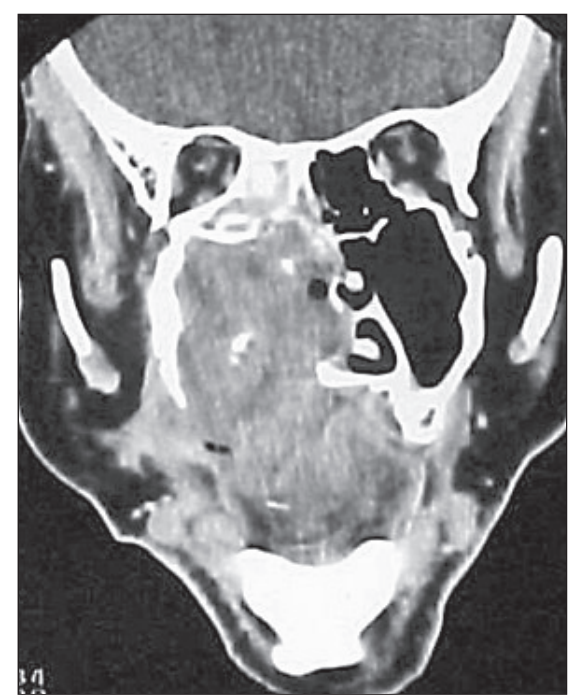

Figura 4. Carcinoma espinocelular de palato duro. Corte coronal de tomografia computadorizada, janela de partes moles. Massa de limites mal definidos distendendo amplamente o hemipalato duro direito, com extensão superior para o seio maxilar e fossa nasal, e inferiormente para a cavidade oral.

pela neoplasia, o procedimento cirúrgico pode ser modificado. Se há invasão do periósteo, este é removido com margem de segurança. Se há invasão do periósteo e da camada cortical, remove-se esta última. $\mathrm{Se}$ houver invasão da camada medular, há a necessidade de ressecção do segmento da mandíbula.

\section{Língua}

Os dois terços anteriores da língua delimitam-se posteriormente na linha da papila circunvalada, a partir da qual se encontra a base da língua, pertencente à orofaringe. Estende-se anteriormente até a superfície inferior no nível da junção com o soalho bucal, livremente móvel. É constituída por quatro feixes musculares intrínsecos que se interdigitam bilateralmente à linha média, além de três pares de músculos extrínsecos.

A musculatura intrínseca é constituída pelas fibras longitudinais superiores e inferiores, que se estendem desde a ponta até a base da língua; existem as fibras transversais e fibras verticais que se estendem inferiormente a partir do dorso da língua e que se interdigitam com fibras transversais, sem ponto de fixação óssea. A TC mostra uma massa arredondada, com aspecto homogêneo, sem planos faciais ou direção regular de seus feixes. A RM evidencia melhor seu baixo sinal, em virtude do melhor contraste de tecidos moles dado por orientações características dos feixes musculares e aparência lamelar condicionada pelo tecido fibroadiposo de alto sinal circundante. Em cortes axiais esta musculatura pode ser grosseiramente confundida com uma massa. O plano sagital é o que permite a melhor compreensão da anatomia local. Nas imagens pesadas em T2 nota-se redução homogênea da intensidade de sinal dessa musculatura.

A musculatura extrínseca da língua é constituída pelos músculos genioglosso, hioglosso e estiloglosso, que formam a porção inferior da língua, promovendo pontos de fixação, e ajudam a compor o soalho bucal. O músculo genioglosso pode ser mais bem estudado em cortes axiais na TC e em cortes axiais e sagitais na RM, pois demonstra a grande quantidade de tecido gorduroso entre as fibras deste músculo, distribuída em forma de leque, no plano sagital, dentro do corpo da língua e representando sua maior porção. O músculo hioglosso tem sua origem no osso hióide, estendendo-se vertical e superiormente, interdigitando-se com o músculo estiloglosso à medida que penetra na face póstero-lateral da língua; separa o ducto submandibular e o nervo lingual, situado profundamente. Este conhecimento é importante no planejamento da glossectomia parcial. O músculo estiloglosso, bem demonstrado em cortes axiais de RM, possui forma arqueada e localização lateral ao músculo genioglosso. Estende-se desde o processo estilóide e divide-se em feixes de fibras que se dirigem à margem lateral da língua e ao músculo hioglosso, interdigitando-se com as fibras deste último.

Os músculos hioglosso e estiloglosso são de difícil diferenciação nas imagens, sendo comumente designados como complexo hioglosso-estiloglosso.

Em geral, lesões da língua anterior têm prognóstico mais favorável do que o carcinoma de base da língua, sendo que esta última pertence à orofaringe. Grandes tumores da língua anterior podem invadir o sulco glossotonsilar, base da língua, fossa tonsilar e soalho da boca.

A RM pode fornecer dados mais precisas sobre a extensão da neoplasia e a relação desta com o feixe neurovascular ${ }^{(\mathbf{1 3}, \mathbf{1 4})}$.

\section{Mucosa bucal}

O carcinoma pode seguir ao longo dos planos profundos dos músculos bucinadores, para dentro dos tecidos subcutâneos da bochecha e posteriormente para o trígono retromolar.

A infiltração do músculo pterigóide médio causa trismo.

Carcinomas localizados na gengiva freqüentemente ocorrem na região de prémolares e molares, com invasão dos alvéolos dentários e da mandíbula, levando a erosões e perdas dentárias ${ }^{(2)}$.

\section{Região do trígono retromolar}

Representa a mucosa que reveste o ramo ascendente da mandíbula, estendendo-se da superfície posterior do último molar até o ápice superiormente, adjacente à tuberosidade da maxila. Tem limites imprecisos, continuando-se com a mucosa bucal, pilar anterior da tonsila e palato mole.

Um grande carcinoma da região retromolar pode se disseminar ao longo da rafe pterigomandibular em direção à fossa infratemporal.

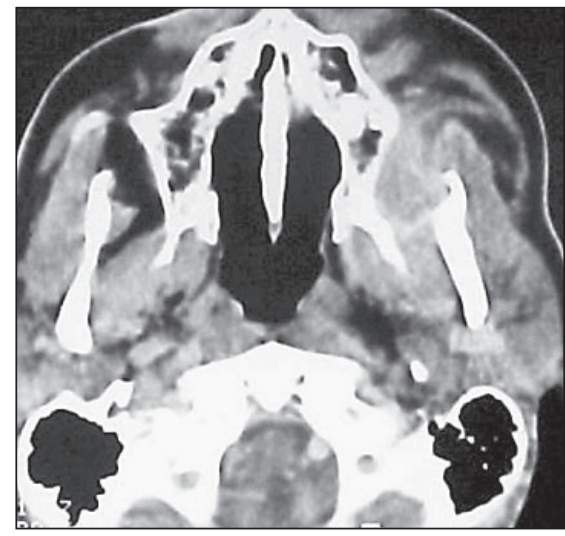

Figura 5. Carcinoma espinocelular do trígono retromolar. Corte axial de tomografia computadorizada, janela de partes moles. Notar massa com densidade de partes moles, de limites mal definidos, ocupando a região do trígono retromolar à esquerda.

\section{Soalho da boca}

É o espaço semilunar que se estende desde a superfície interna da borda alveolar inferior até a superfície inferior da língua, tendo seu limite posterior na base do pilar anterior da tonsila. Sua porção anterior é dividida em dois lados pelo frênulo da língua e contém o óstio das glândulas submandibular e sublingual. 
Esta região é composta por vários músculos, estudados a seguir.

O músculo milo-hióideo é a principal estrutura de suporte do soalho bucal; tem origem na linha milo-hióidea da superfície medial da mandíbula, desde o terceiro molar até a sínfise mentoniana. Estende-se caudalmente até a linha média, inserindose na rafe mediana, exceto em sua porção posterior, que se insere na superfície anterior do osso hióide. Separa o espaço submandibular, lateralmente, do espaço sublingual, medialmente. Devido à sua discreta obliqüidade ao plano axial, é mais bem demonstrado em cortes coronais.

O músculo genio-hióideo tem origem no tubérculo geniano inferior da sínfise mentoniana, estendendo-se medialmente ao músculo milo-hióideo e inserindo-se na margem superior do corpo do osso hióide; é mais bem demonstrado em cortes axiais.

O ventre anterior do músculo digástrico tem origem no tendão intermediário, no anel fibroso ao lado do osso hióide, tendo inserção na fossa digástrica, na margem inferior da mandíbula, lateralmente à linha média. As imagens coronais e axiais mostram sua disposição látero-inferior em relação ao músculo milo-hióideo.

Temos ainda os músculos extrínsecos da língua, três de cada lado da linha média, e que já foram citados anteriormente.

O CEC de soalho da boca é o segundo tumor mais comum na cavidade oral e a porção anterior é o sítio de origem mais freqüente. Em até 5\% dos casos são originários das glândulas salivares sublinguais. Esses tumores podem também se estender para os espaços sublingual e submandibular. A infiltração ao longo do periósteo da mandíbula costuma ocorrer precocemente no curso da doença. A destruição da mandíbula pode ocorrer tardiamente, com a invasão dos forames mentonianos ou alveolares inferiores. A artéria lingual é freqüentemente envolvida. A obstrução do ducto submandibular resulta em aumento inflamatório da glândula. A invasão dos nervos hipoglosso ou lingual pode levar a alterações motoras, sensitivas e atrofia ${ }^{(9)}$.

Na TC, a glândula submandibular possui densidade similar aos músculos. Já na RM, mostra intensidade de sinal intermediária entre tecido muscular e gorduroso nas seqüências pesadas em T2. Os $3 \mathrm{~mm}$ ou

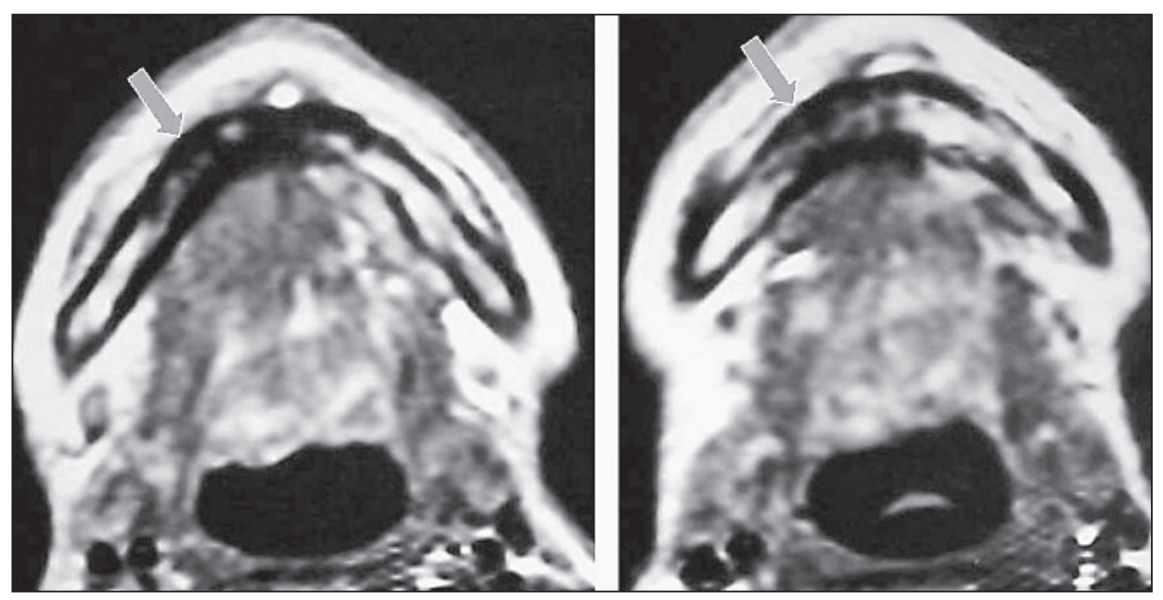

Figura 6. Carcinoma espinocelular de soalho da boca. Cortes axiais de ressonância magnética, ponderação em T1. Massa com intensidade de sinal intermediária na porção anterior do soalho da boca à direita. Notar a presença do mesmo material com intensidade de sinal intermediária obliterando o conteúdo gorduroso da cavidade medular da mandíbula adjacente (setas).

$4 \mathrm{~mm}$ proximais do ducto submandibular podem ser vistos normalmente, como uma estrutura tubular deixando a porção profunda da glândula, medialmente ao músculo milo-hióideo ${ }^{(15)}$.

\section{CONCLUSÃO}

A maioria dos tumores da cavidade oral é de células escamosas, tendo como sítios mais freqüentes o lábio e o soalho da boca.

Por meio da RM e da TC pode-se definir o tamanho, a localização e a extensão do tumor.

As características dos tumores na TC e na RM, tais como intensidade de sinal, contrastes e heterogeneidade, não são preditivos para a diferenciação entre tumores benignos e malignos. Poucas lesões demonstram densidades características na TC. Também lesões inflamatórias, muitas vezes, não podem ser diferenciadas dos tumores.

Pequenos tumores são mais difíceis de serem detectados. Normalmente a RM oferece maior sensibilidade que a TC na evolução de pequenos tumores, enquanto a TC avalia melhor o envolvimento ósseo.

\section{REFERÊNCIAS}

1. Carvalho MB, Fava AS. Tumores malignos da cavidade oral. In: Brandão LG, Ferraz AR, eds. Cirurgia de cabeça e pescoço. São Paulo: Livraria Rocca, 1989:299-305.

2. Souza RP. Diagnóstico por imagem na avaliação do câncer de boca. São Paulo: Livraria Pancast, 1997: 137-52.
3. Dillon WP. The pharynx and oral cavity. In: Som PM, Bergeron RT, eds. Head and neck imaging. 2nd ed. St. Louis: Mosby-Year Book, 1991:407-66.

4. Lenz M, Greess H, Baum U, Dobritz M, KerstingSommerhoff B. Oropharynx, oral cavity, floor of the mouth: CT and MRI. Eur J Radiol 2000;33: 203-15.

5. Kassel EE, Keller MA, Kucharczyk W. MRI of the floor of the mouth, tongue and orohypopharynx. Radiol Clin North Am 1989;27:331-51.

6. Larsson SG, Mancuso A, Hanafee W. Computed tomography of the tongue and floor of the mouth. Radiology 1982;143:493-500.

7. Becker M. Oral cavity, oropharynx, and hypopharynx. Semin Roentgenol 2000;35:21-30.

8. Baker HW. Staging of cancer of the head and neck: oral cavity, pharynx, larynx and paranasal sinuses. Cancer J Clin 1983;33:130-3.

9. Korobkin M, Kressel HY, Moss AA, Koehler RE. Computed tomographic angiography of the body. Radiology 1978;126:807-11.

10. Aspestrand F, Kolbenstvedt A, Boysen M. Staging of carcinoma of the palatine tonsils by computed tomography. J Comput Assist Tomogr 1988;12: 434-7.

11. Byrd SE, Schoen PJ, Gill G, Richardson M. Computed tomography of palatine tonsillar carcinoma. J Comput Assist Tomogr 1983;7:976-82.

12. Muraki AS, Mancuso AA, Harnsberger HR, Johnson LP, Meads GB. CT of the oropharynx, tongue base, and floor of the mouth: normal anatomy and range of variations, and applications in staging carcinoma. Radiology 1983;148:725-31.

13. Vogl T, Bruning R, Grevers G, Mees K, Bauer M, Lissner J. MR imaging of the oropharynx and tongue: comparison of plain and Gd-DTPA studies. J Comput Assist Tomogr 1988;12:427-33.

14. Ozturk M, Yorulmaz I, Guney E, Ozcan N. Masses of the tongue and floor of the mouth: findings on magnetic resonance imaging. Eur Radiol 2000;10: 1669-74.

15. Daura Saéz A, Rodriguez San Pedro F, Asenjo Garcia B, Aparicio Cambreros J, Valiente Alvarez A. Magnetic resonance imaging in the diagnosis of oral carcinoma. Acta Otorrinolaringol Esp 1999; 50:283-90. 